\title{
SUSPECTED MEDULLARY THYROID CANCER IN A PATIENT WITH NEUROENDOCRINE TUMOR OF LEFT LUNG.
}

Elżbieta Andrysiak-Mamos, Elżbieta Sowińska-Przepiera, Bartosz Kiedrowicz, Ewa Żochowska,

\& Anhelli Syrenicz

'Department of Endocrinology, Metabolic and Internal Diseases, Pomeranian Medical University, Szczecin, Poland

\section{Introduction}

Despite recommendations neuroendocrine tumors may still pose diagnostic and therapeutic problems. Patients are referred to specialized centers when their disease has already progressed to generalized stage.

\section{CASE REPORT}

A 64-year old male patient was referred to the Department of Endocrinology at the Pomeranian Medical University in 2013 because of liver metastases. His medical history included a surgical treatment of left lung tumor in 2006 with histopathology: Typical carcinoid (Ki67 12\% G2, T3N1M0). The patient has suffered from the symptoms of carcinoid syndrome for a few years. He has had abdominal pain for one year. Ultrasound and CT scan of the abdomen suggested the suspicion of liver metastases which was later confirmed by histopathology findings in core-needle biopsy specimen - neuroendocrine tumor with Ki 67 ranging from 17 to $31 \%$. CT scan of the chest ruled out local recurrence and metastases in the right lung. Receptor scintigraphy - NET metastases. High levels of tumor markers were also observed (chromogranin $879 \mathrm{ng} / \mathrm{ml}, 5-\mathrm{HIA}$ acid $181 \mathrm{mg} / 24 \mathrm{~h}$, calcitonin $387 \mathrm{pg} / \mathrm{ml}$, CEA 6.47, AFP $3.44 \mathrm{IU} / \mathrm{ml}$ ). Ultrasound of the thyroid gland revealed several hypoechogenic foci in both lobes, their sizes ranging from 3 to $10 \mathrm{~mm}$. A medullary thyroid cancer was suspected based on fineneedle biopsy and high calcitonin levels. Thyroidectomy was performed. Histopathology investigation revealed multiple foci of neuroendocrine tumor in both thyroid lobes, with the Ki67 proliferation marker ranging from 7 to $22 \%$, ruling out the diagnosis of medullary cancer based on negative calcitonin staining. The patient was treated with somatostatin analogues with good clinical effect and with PRRT because of disease progression confirmed in imaging examinations.

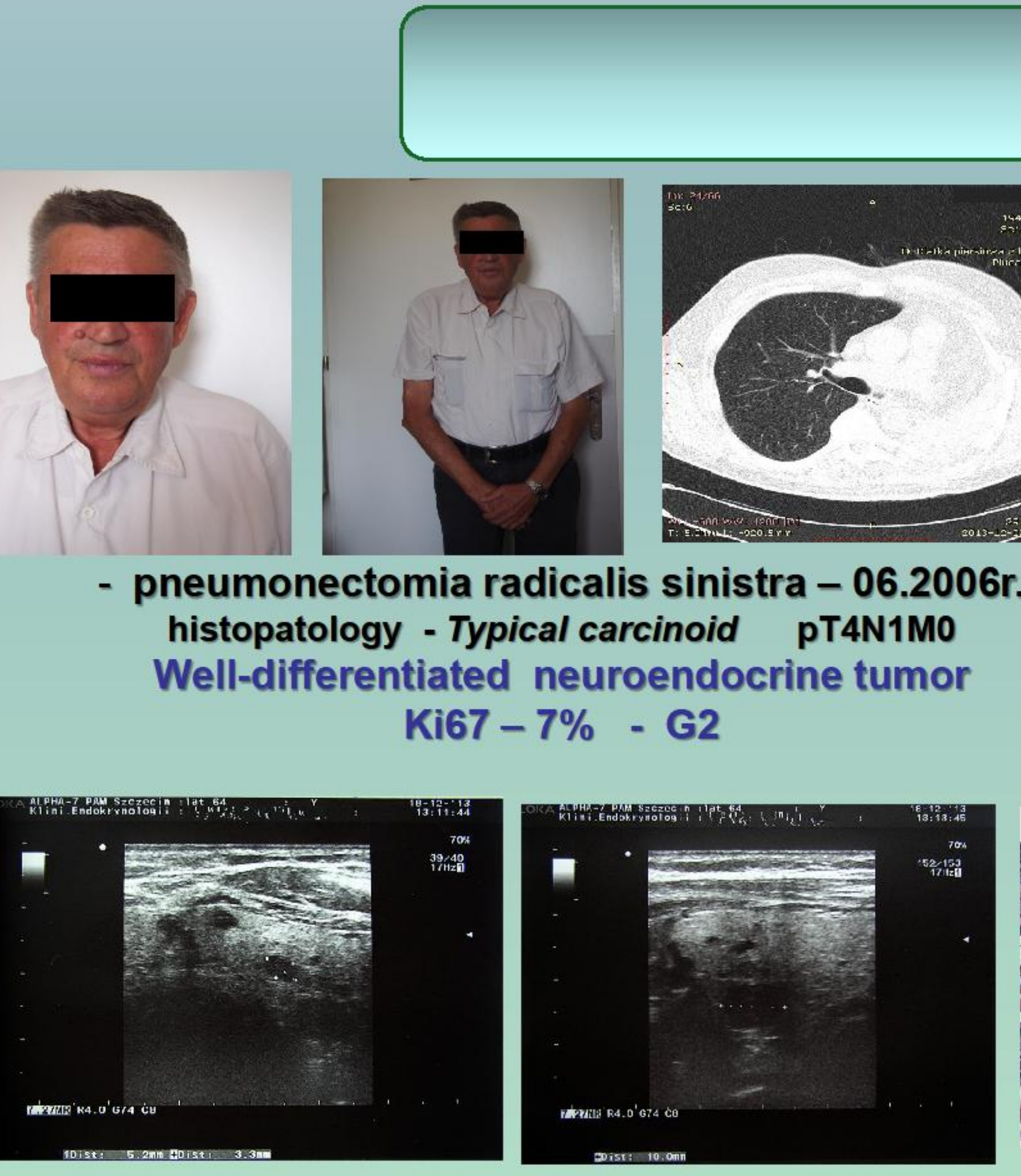

Thyroid metastases of TLC in thyroid ultrasound

\section{Results}

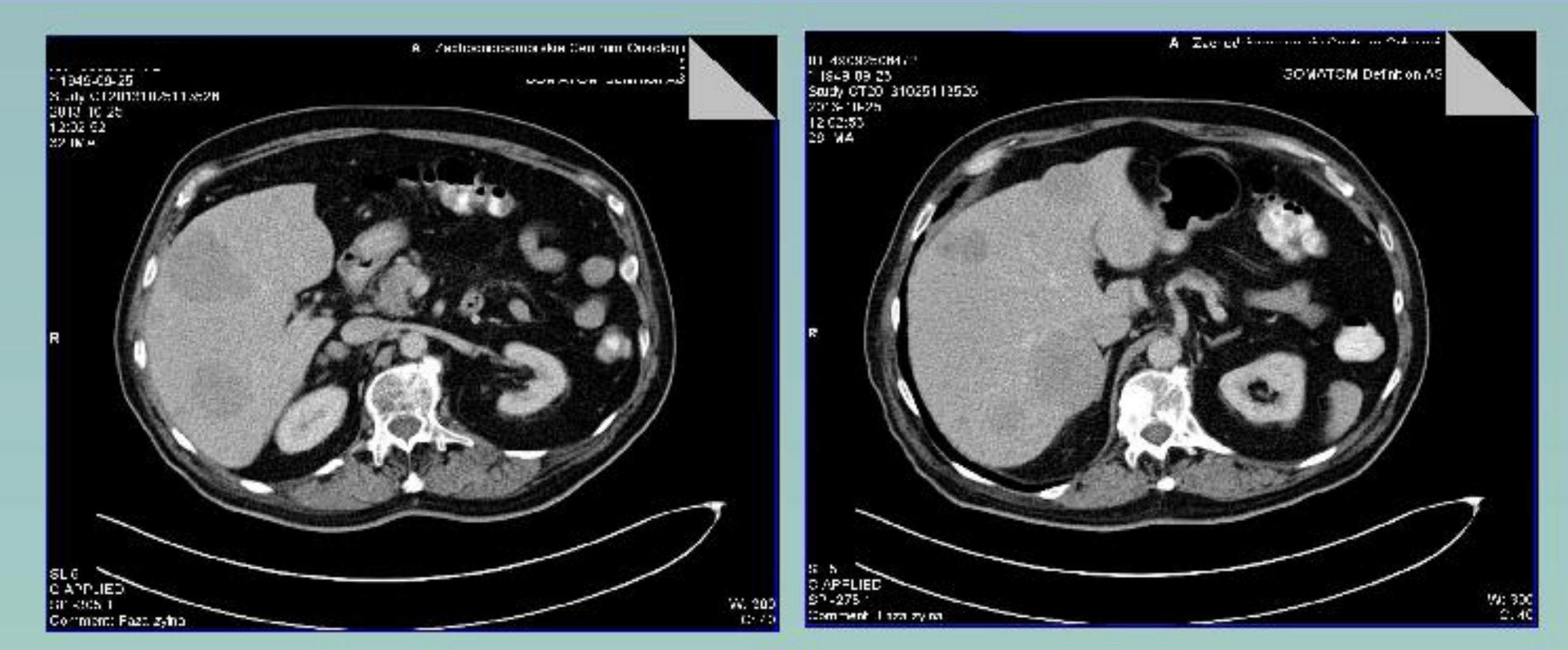

Liver and vertebral metastases of typical lung carcinoid (TLC) in abdominal CT scan (largest lesions: $5.8 \mathrm{~cm}$ and $5.5 \mathrm{~cm}$ )

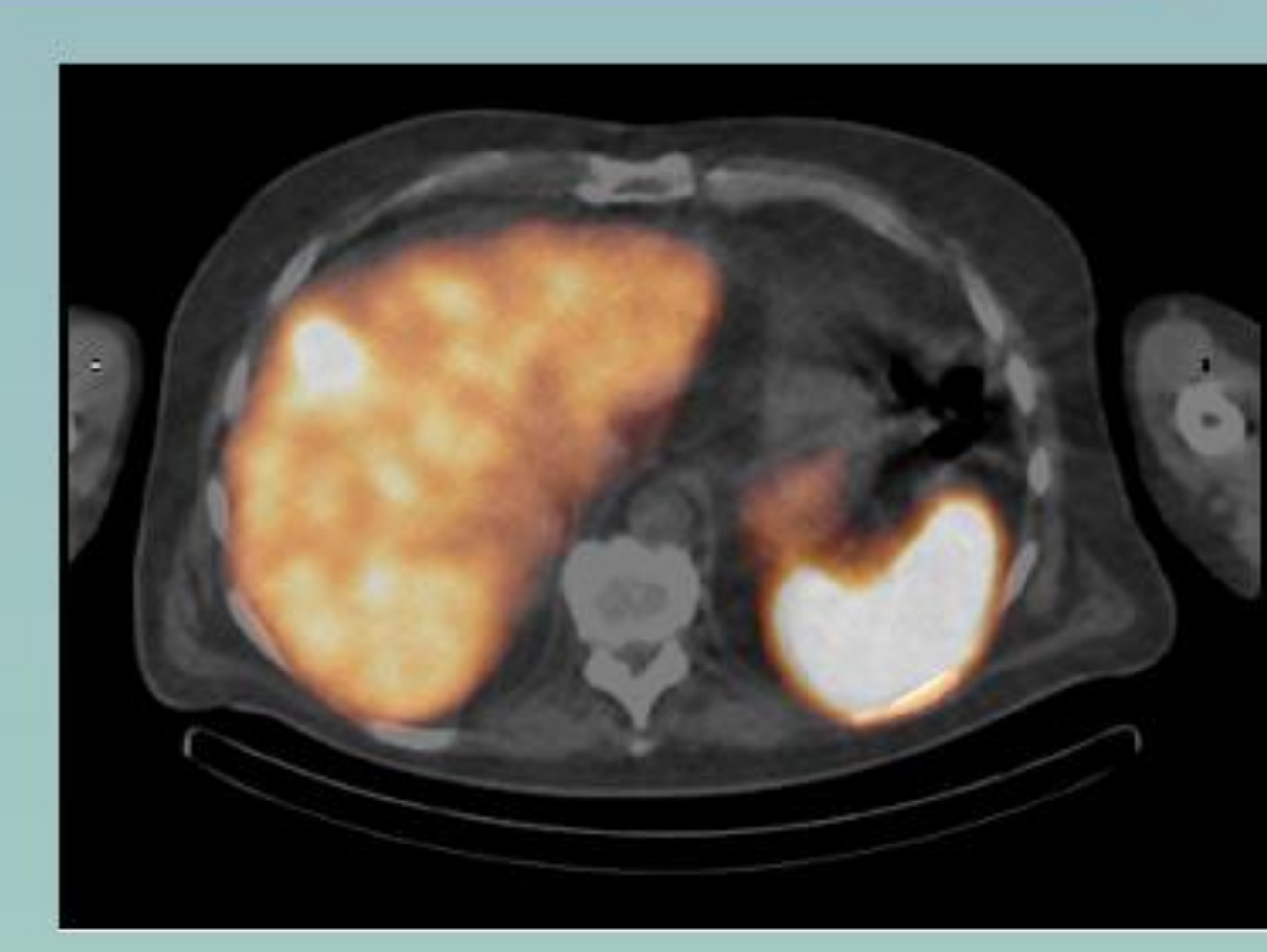

Somatostatin receptor scintigraphy (octreoscan) - liver and vertebral metastases

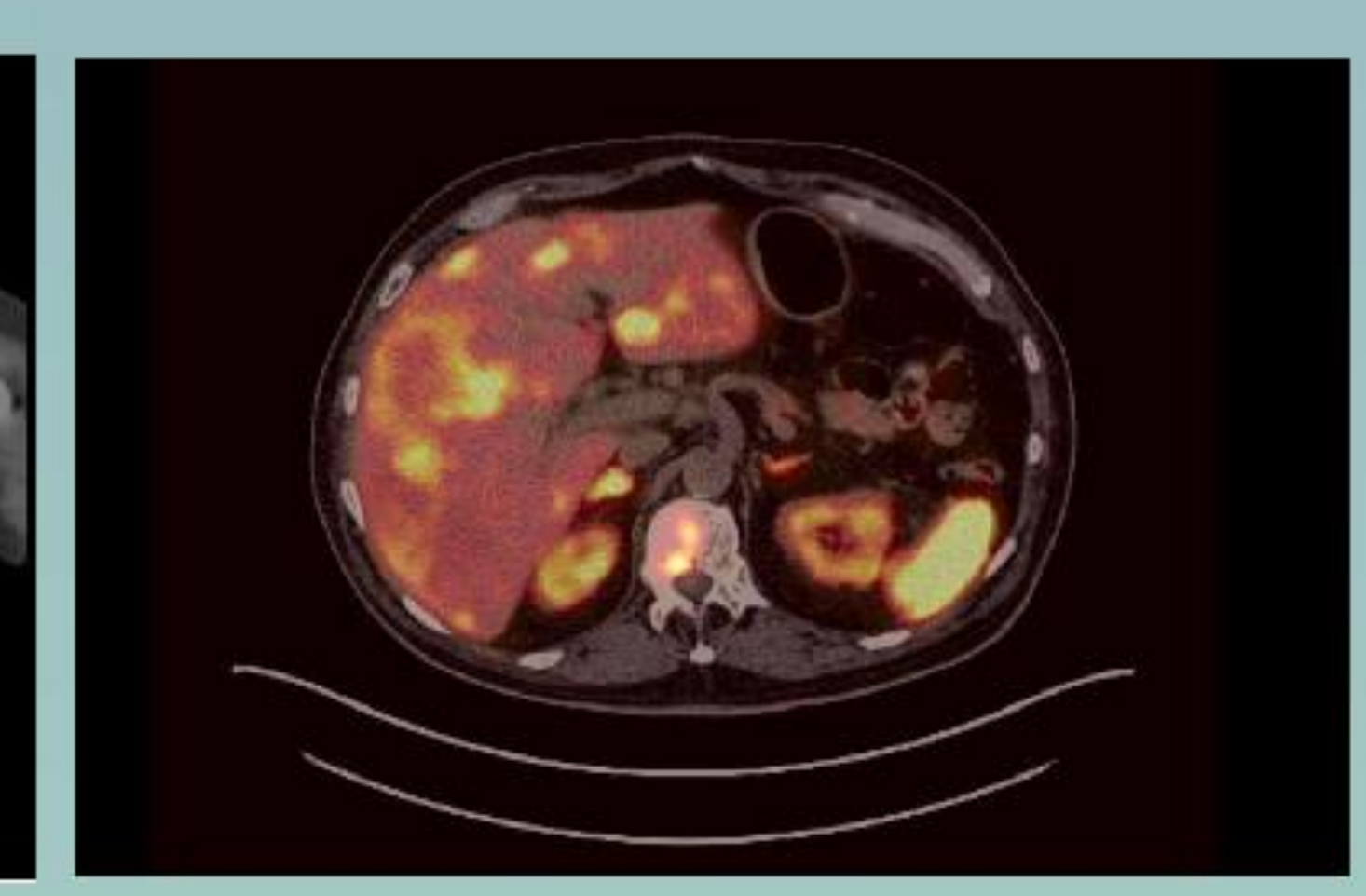

Ga68-DOTATATE PET/CT liver and vertebral metastases

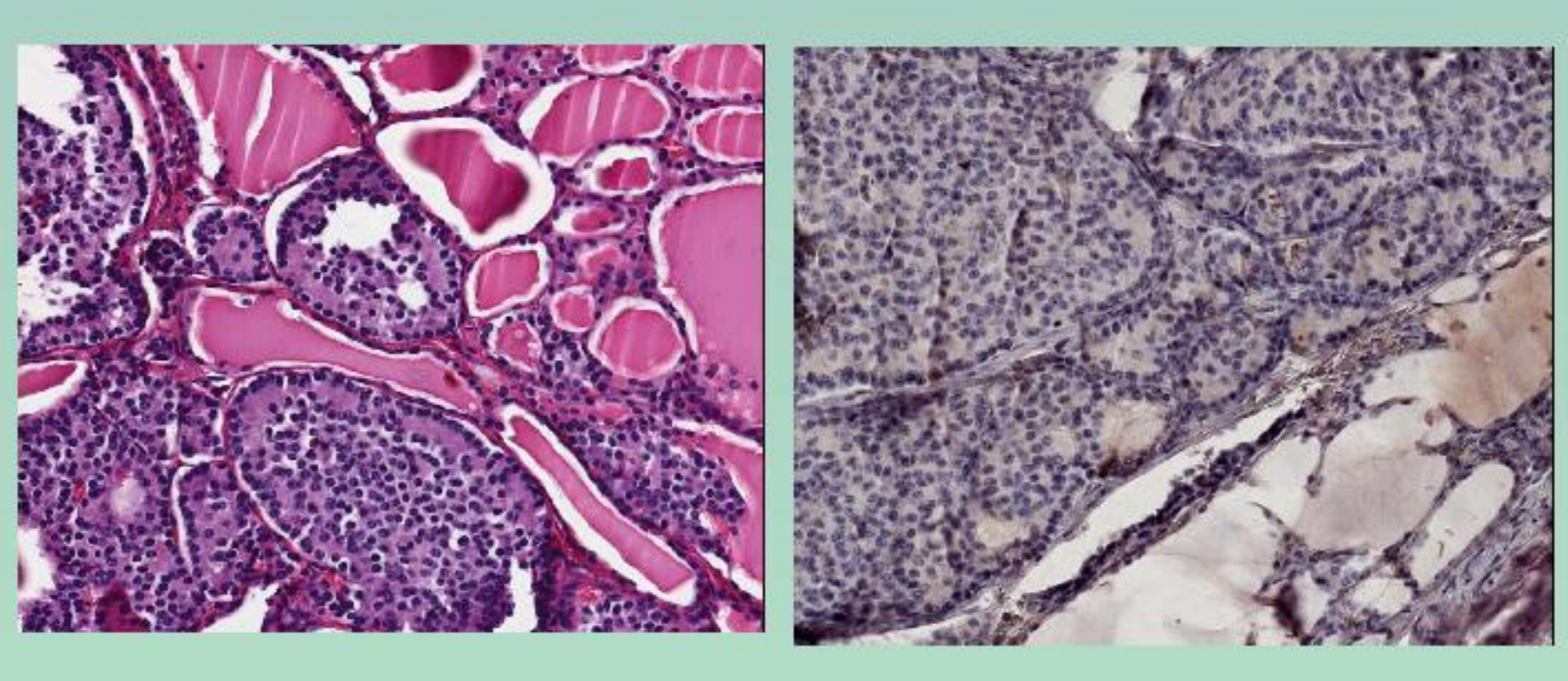

stain for calcitonin

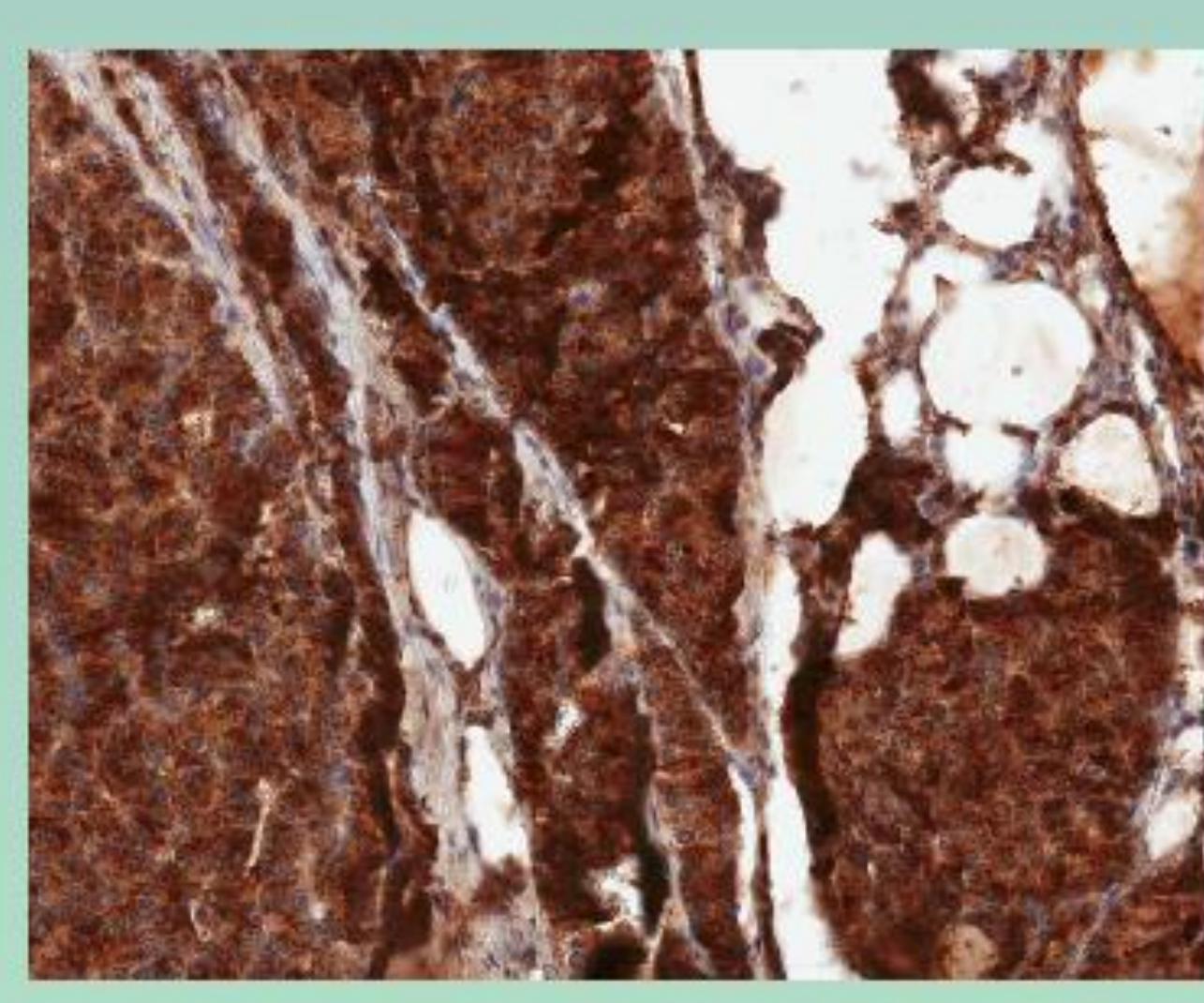

stain for chromogranin

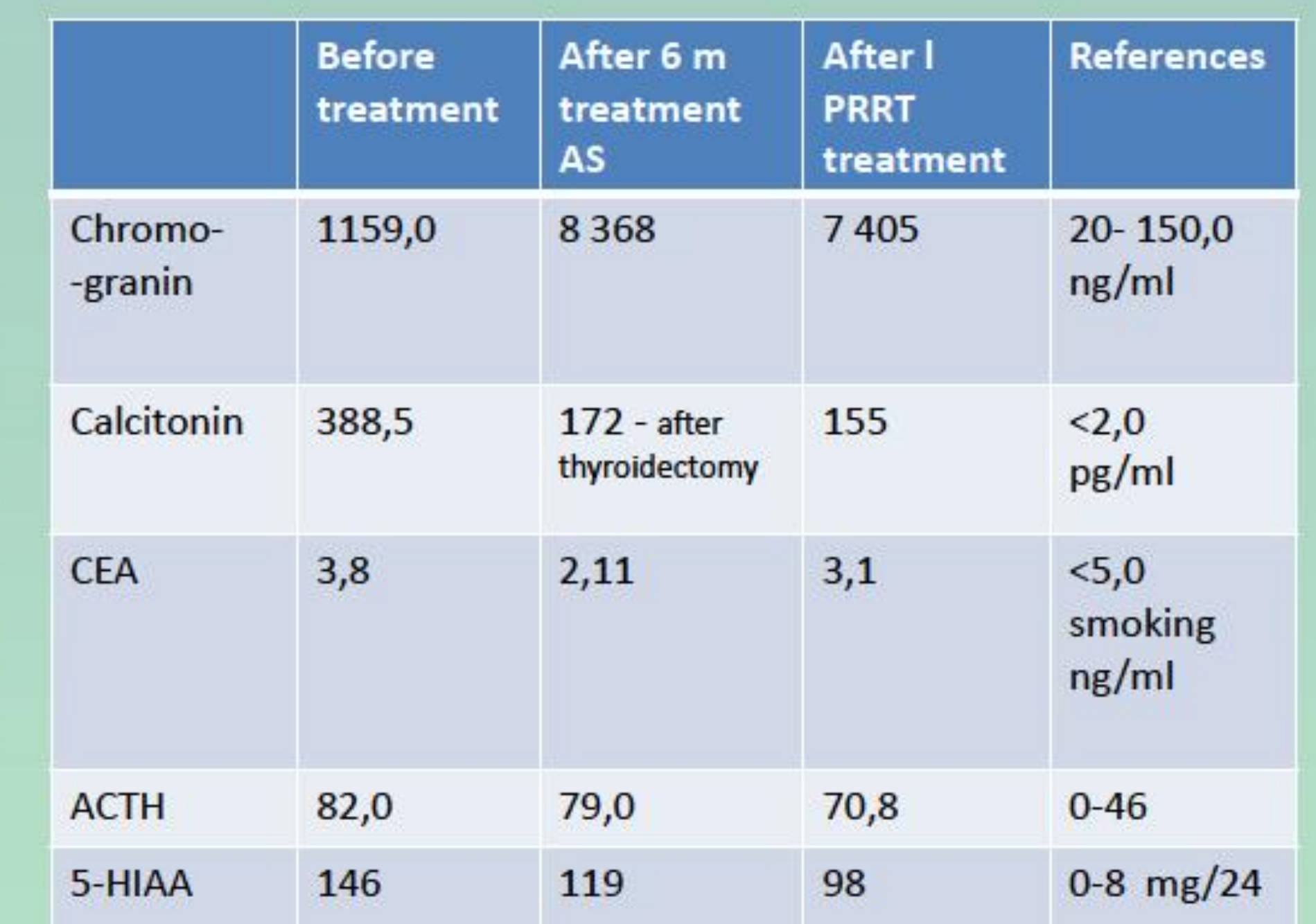

\section{LABORATORY RESULTS}

\begin{tabular}{lllll} 
& & References & UNIT \\
\hline 5-HIAA & $\begin{array}{l}1-168,0 \\
11-147,0\end{array}$ & $0-8,0$ & $\mathrm{mg} / 24 \mathrm{~h}$ \\
Chromogranin & 1159,0 & $20-150,0$ & $\mathrm{ng} / \mathrm{ml}$ \\
Calcitonin & $\mathbf{3 8 8 , 5}$ & $<2,0$ & $\mathrm{pg} / \mathrm{ml}$ \\
CEA & 3,8 & $<5,0$ palqcy & $\mathrm{ng} / \mathrm{ml}$ \\
AFP & 3,44 & $0,0-5,8$ & $\mathrm{IU} / \mathrm{ml}$ \\
\hline
\end{tabular}

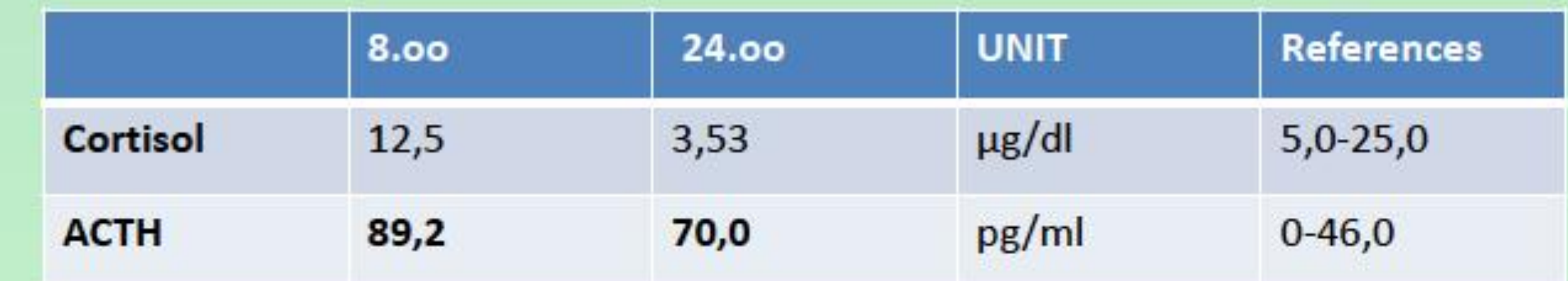

\begin{tabular}{l|l|l|l} 
& Levels & References & UNIT \\
\hline TSH & 1,81 & $0,27-4,2$ & $\mathrm{mlU} / \mathrm{ml}$ \\
\hline fT3 & 2,97 & $2,0-4,4$ & $\mathrm{pg} / \mathrm{ml}$ \\
\hline fT4 & 1,24 & $0,93-1,7$ & $\mathrm{ng} / \mathrm{dl}$ \\
\hline antyTPO & 16,8 & $7,63-42,6$ & $\mathrm{pg} / \mathrm{ml}$ \\
\hline antyTG & 11,2 & $0,70-3,6$ & $\mathrm{ng} / \mathrm{ml}$ \\
\hline PTH & 32,0 & $11-67$ & $\mathrm{pg} / \mathrm{ml}$ \\
\hline Thyroglobulin & 33,6 & $11-58$ & \\
\hline
\end{tabular}

\begin{tabular}{|l|l|l|l|}
\hline & Levels & References & Unit \\
\hline ALAT & 27 & $0-41$ & $\mathrm{U} / \mathrm{I}$ \\
\hline AspAT & 17 & $0-38$ & $\mathrm{U} / \mathrm{I}$ \\
\hline GGTP & $\mathbf{1 6 1}$ & $9-60$ & $\mathrm{U} / \mathrm{I}$ \\
\hline ALP & $\mathbf{1 3 5}$ & $40-130$ & $\mathrm{U} / \mathrm{l}$ \\
\hline Total Ca & $\mathbf{2 , 6 2}$ & $2,20-2,55$ & $\mathrm{mmol} / \mathrm{I}$ \\
\hline lonized Ca & $\mathbf{1 , 4 1}$ & $\mathbf{1 , 1 2 - 1 , 3 2}$ & $\mathrm{mmol} / \mathrm{I}$ \\
\hline HbA1c & $\mathbf{6 , 8 8}$ & $4,8-5,9$ & $\%$ \\
\hline
\end{tabular}

\section{Conclusions}

High calcitonin levels and suspected medullary thyroid cancer in fine-needle aspiration biopsy of focal thyroid lesions sampled from a patient with NET do not rule out thyroid metastases associated with the underlying disease.

$\frac{\text { Metastatic neuroendocrine tumors to the thyroid gland mimicking medullary carcinoma: a pathologic and immunohistochemical study of six cases. }}{\text { Matias-Guiu X, LaGuette J, Puras-Gil AM, Rosai J. Am J Surg Pathol. } 1997 \text { Jul;21(7):754-62. }}$

Thyroid metastases from typical carcinoid of the lung differentiating between medullary thyroidcarcinoma and neuroendocrine tumor metastasis to the thyroid. La Rosa S, Imperatori A, Giovanella L, Garancini S, Capella C. Thyroid. 2009 May;19(5):521-6. doi: 10.1089/thy.2008.0424 